\title{
AgriCat: An One-stop Shop for OAI-based Open Access Agricultural Repositories
}

\author{
Bijan Kumar Roy ${ }^{1}$, Subal Chandra Biswas ${ }^{2}$, Parthasarathi Mukhopadhyay ${ }^{3}$
}

\begin{tabular}{|c|c|}
\hline I N F O & A B S T R A C T \\
\hline Received 5 Mar. 2016 & \\
\hline Accepted 28 Apr. 2016 & The paper gives an overview of open access (OA) institutional digital repositories (IDRs) \\
\hline Available on-line 30 Apr. 2016 & in agricultural fields. The main objective is to provide free and unrestricted access to the \\
\hline Responsible Editor: M. Herdon & $\begin{array}{l}\text { public funded research outputs in global-scale in the domain of agricultural by developing } \\
\text { a single window search interface as a useful tool for agricultural researchers in developing }\end{array}$ \\
\hline Keywords: & countries with special reference to India keeping in view the exorbitant cost of research \\
\hline Agriculture, Agricultural & output. It reports the design and development of a federated search interface, viz. AgriCat \\
\hline Sciences, Resource Discovery, & that facilitates resource sharing through extracting metadata from different OAI (Open \\
\hline Metadata Harvesting, & Archives Initiative) compatible agricultural IDRs registered in OpenDOAR (Directory of \\
\hline Institutional Repository. & \\
\hline
\end{tabular}

\section{Introduction}

Agriculture as a subject and as a discipline has become an important field of research among academic communities. Agriculture is one of the key sectors of an economy which provides the basic needs of people for food as well as larger employment opportunities. Agriculture is the backbone of the economy of the majority of the developing countries like India and a large number of people (almost 75\%) depend on it for their livelihood. India has a comprehensive agricultural education and research system. There are sixty five agricultural universities (including 5 deemed universities and 2 central universities recognized by the Indian Council of Agricultural Research) and more than 200 colleges, which offer various courses in agriculture and allied subjects ( $h t t p: / / w w w . i n d i a c o l l e g e s h u b$ .com/top-agricultural-universities-india.aspx). A good number of agricultural learning repositories have already been developed worldwide (http://www.fao.org/3/a-ai264e.pdf). And India is not the exception. In 2006, the first AGRIS (International System for Agricultural Science and Technology) workshop on open access (OA) in agricultural sciences and technology held at ICRISAT (International Crops Research Institute for the Semi-Arid Tropics), Hyderabad. The first repository for agricultural sciences was initiated in 2008 under the name 'Krishiprabha'. It holds all the doctoral dissertations submitted to various agricultural universities in India. In 2009, another important move in this regards was the establishment of open access repository (OAR) in agricultural sciences with the help of ICRISAT (Roy, Biswas \& Mukhopadhyay 2016a).

$\mathrm{Bu}$ these are distributed across the globe with different software architecture bundled with different retrieval technique. It creates a serious retrieval problem for end users. So, current research outputs acquired by these repositories in agricultural sciences and allied fields need to be shared with researchers, scientists, and academicians all over the world. In this sense, there is a growing need for coordination and cooperation among different academic and research institutes working in these fields

\footnotetext{
$1 \quad$ Bijan Kumar Roy

Department of Library and Information Science, The University of Burdwan, West Bengal, India bijankumarroy@yahoo.co.in

$2 \quad$ Subal Chandra Biswas

Department of Library and Information Science, The University of Burdwan, West Bengal, India scbiswas_56@yahoo.co.in

3 Parthasarathi Mukhopadhyay

Department of Library and Information Science, University of Kalyani, West Bengal, India psmukhopadhyay@gmail.com
} 
and research outputs in the form of theses, projects, reports, etc. created by various organizations in different languages need to be distributed globally (Roy, Biswas \& Mukhopadhyay 2016a). From this perspective, the development and promotion of a global infrastructure is required with the objective of sharing and reusing of scholarly resources on topics related to agricultural and rural development (http://www.fao.org/3/a-ai264e.pdf).

Due to the advancement of information communication technologies and particularly the development of open source software (OSS), federated searching has quickly become an invaluable tool for digital library systems. The open access to knowledge movement, which started in the 1990s after the advent of WWW (World Wide Web) and Internet, influenced the emergence of new resource discovery platforms for sharing bibliographic records between these OAI (Open Archives Initiative)based information retrieval systems. Now resources are being generated in an open manner and it has become quite difficult to archive, preserve these knowledge objects in a centralized system that would support distributed processing and distributed access to resources globally. From researchers' point of view, they are not familiar with different distributed (OA publishing platforms such as open access repositories (OARs) or open access journals (OAJs) etc. They are having difficulties to find what is available to them and need to learn how to access each interfaces. Besides, their expectations towards OA resources are also changing significantly and they would like to have it through a single search interface (Sarkar \& Mukhopadhyay 2010). They prefer to have a gateway that would give free full text access to the public funded research outputs in their domain through a single access point (Sarkar \& Mukhopadhyay 2012a).

So, a need arises among researchers to manage and maintain scholarly objects in an organized and accessible manner in a web-enabled distributed system. Here lies the importance of preserving such knowledge resources in an online interoperable information retrieval system for perpetual access. But, these valuable resources are underutilized and inaccessible due to the absence of suitable resource discovery tool. Existing information retrieval systems are not well suited for this purpose, particularly in the domain for agricultural sciences. A comprehensive federated search service for all the OA repositories in the country has not been attempted as yet. In keeping in mind the requirements of the researchers, this model e.g AgriCat based on open standard (OS) and OSS may be considered as an alternative platform that facilitates resource sharing through harvesting bibliographic records from OAI-based repositories on global scale. It is basically a metadata harvesting, search and retrieval tool that enables information to be accessed, preserved and disseminated far more easily than ever before.

The objective of the paper is to provide an overview of the existing resource discovery systems and outlines the innovative use of the model (e.g. AgriCat) along with its key features. It is presented here as a centralized repository of metadata with distributed data sources, the objective of which is to harvest metadata from various data providers and making knowledge resources available through a single access point. In this context, AgriCat may be considered as a union catalogue containing OA records from multiple OAI-based agricultural OARs that would provide one-stop shop to multiple information sources for researchers searching resources in the domain of agricultural sciences.

\section{Literature Review}

The growth of repositories as Green road (also known as self archiving) to OA has been rapid throughout the world and has emerged as a new publishing tool in order to provide seamless access to the world's research output (Roy 2015). To strengthen the repository movement in this domain in order to exchange, share and reuse of scientific research results among researchers, several projects were launched and a number of initiatives were taken to expose their datasets in public domain (Roy, Biswas \& Mukhopadhyay 2016a). GODAN (Global Open Data for Agriculture and Nutrition) is an initiative that seeks to support global efforts to make data relevant to agriculture and nutrition available, accessible, and usable for unrestricted use worldwide (http://www.godan.info). AGRIS is one of the most important world-wide information system in the area of the agricultural sciences (http://agris.fao.org/agris-search/index.do). One of the main objectives of AGRIS is to improve the access and exchange of information serving the information-related needs of developed and developing countries on a partnership basis (http://agris.fao.org/content/about). It may safely be said 
that AGRIS started a movement to open up agrcultural research output to scientists and academia from developing countries in eighties and that initiative acted as a forerunner to triger almost all the countries in the world for developing and maintaining OARs to promote and support research in agricultural domain (OpenDOAR 2016; ROAR 2016). Several papers reported the repository movement in India (Roy 2007, 2010, 2014b; Roy, Biswas \& Mukhopadhyay 2012a, 2012b, 2012d, 2013, 2016d) as well as abroad such as Europe (Roy, Biswas \& Mukhopadhyay 2015), North America (Roy, Biswas \& Mukhopadhyay 2016b). Couple of authors have emphasized on maintaining domain specific subject repository such as in agriculture (Roy, Biswas \& Mukhopadhyay 2016a) and in library and information science (Ganaie et al. 2014; Sengupta 2012; Roy, Biswas \& Mukhopadhyay 2016c). In another paper, Roy and Mukhopadhyay (2011) explained the necessity of maintaining repository for learning objects in India. But finding open access (OA) resources available in different OA channels and searching them separately is a difficult and time consuming task to the researchers (Donaldson \& Nelson 2011). Mukhopadhyay (2015) provided an overview and technical issues related to interoperability in OA contents dissemination along with metadata interoperability and harvesting. Liu et al. (2001) suggested for a unified searching interface that can address this issue by amalgamating different OA sources together and providing a unified interface to perform search queries. Crow (2002) suggested that retrieval systems must be able to support interoperability and able to harvest metadata through multiple search engines and other standard discovery tools in order to provide broader access not only to the academic and research community, but also to users outside the institution. Marcondes and Sayao (2003) put emphasis on forming such cooperative union catalogue with the aim of providing integration and unified access, via a Web gateway. Sarkar and Mukhopadhyay (2010) presented a method of metadata harvesting from different OAI-PMH (Protocol for Metadata Harvesting) compliant repositories containing electronic theses and dissertations. This study developed and described in details harvesting framework using PKP (Public Knowledge Project) harvester. In another paper, authors reported the designing of a prototype union catalogue of ETDs (Electronic Theses and Dissertations) on health and medicine (Sarkar \& Mukhopadhyay 2012a). In the same year in another publication, they showed how metadata helps in organization and retrieval of ETDs (Sarkar \& Mukhopadhyay 2012b). Jayakanth and Minj (2012) shared their practical experiences in setting up a prototype metadata harvesting service using the PKP harvesting software for the OAIcompliant repositories in India. Kumar, Sanaman and Rai (2008) covered various federated search providers along with advantages and drawbacks in federated search. Roy (2014) in his research work designed a prototype namely BURA (Burdwan University Research Archive) using PKP harvester (version 2) that facilitates resource sharing by extracting bibliographic records between OAI-based repositories on global scale. In another work, he opined that this type of web-enabled gateway is useful to the researchers because it provides global access to the resources through a unified search interface (Roy 2015). In a recent study, Sarkar and Mukhopadhyay (2015) reported the development of interoperable ETD repositories in Indian context and concluded that this facilitates resource sharing in the digital library domain and increases discoverability of resources by providing easy access. Of late, Roy, Biswas \& Mukhopadhyay (2016e) reported the development of a prototype using OSS that is applicable to any domain. Several cross search services based on metadata harvesting have already been established in India (Hirwade \& Hirwade 2006; Hirwade \& Bherwani 2011). For example, CASSIR (Cross Archive Search Service for Indian Repositories - http://smart.ncsi.iisc.ernet.in/oai) is the first such attempt in the country to harvest OAI-compatible repositories developed in India irrespective of subject. SDL (Search Digital Libraries - http://drtc.isibang.ac.in/sdl/) is another federated search service related to the library and information science discipline but covers OARs from different parts of the world. SEED (Search Engine for Engineering Digital Repositories http://eprint.iitd.ac.in/seed/) is a federated search service for the engineering discipline (Roy, Biswas \& Mukhopadhyay 2012c).

\section{Agricultural Repositories: Present Situation}

Repository movement was initiated mainly in some developed countries like USA, UK and Germany, but now it has become an area of research among academicians and scientists throughout the world. Now countries in all the continents are maintaining repositories on different subjects and objects. However, majority of the repositories are from Europe and North America. OpenDOAR 
(2016) has recorded 2990 repositories (as on January 2016) all over the world and this field (e.g. 'Agriculture, Food and Veterinary Sciences') having 138 (4.6\%) repositories stand at $16^{\text {th }}$ position. Europe contributes 46 repositories, 31 in the Asia, 19 in North America, 16 each in Africa and South America, and the remaining 13 repositories are from Central America and Australasia (Figure 1). If we consider countries as per number of repositories, India having 5 repositories ranks $8^{\text {th }}$ position in the world (Figure 2).

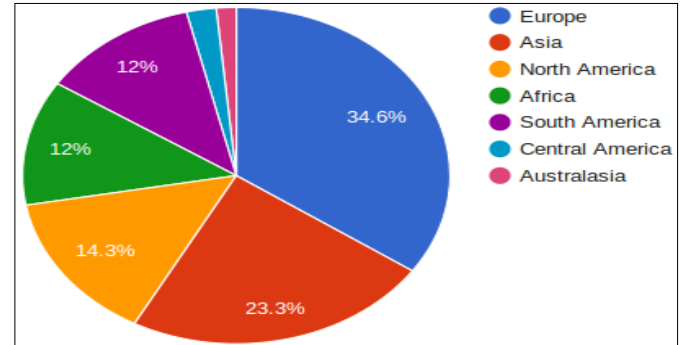

Figure 1. Continent-wise distribution (Source: OpenDOAR)

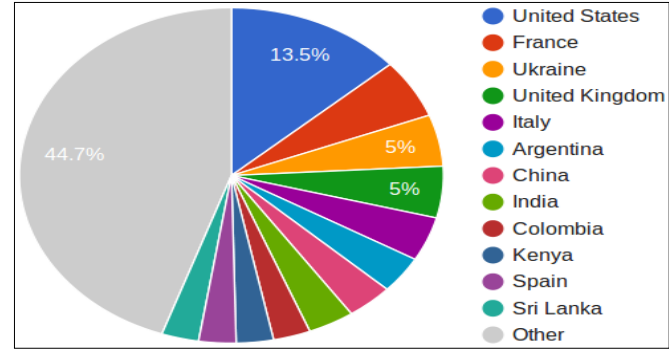

Figure 2. Country-wise distribution (Source: OpenDOAR)

There is a steady growth of OARs in all disciplines including agricultural sciences since 2004 after taking calls from Budapest Open Access Initiative (2002), Berlin declaration (2003) and Bethesda Statement (2003). Figure 3 shows the cumulative growth of agricultural OARs during the last 6 years e.g. 2010 to 2016. Figure 3 suggests that in January 2010, there were only 35 OARs and this number has climbed to more than 138 in January 2016, with an average increase of 16 to 17 new repositories added per year (except 2015).

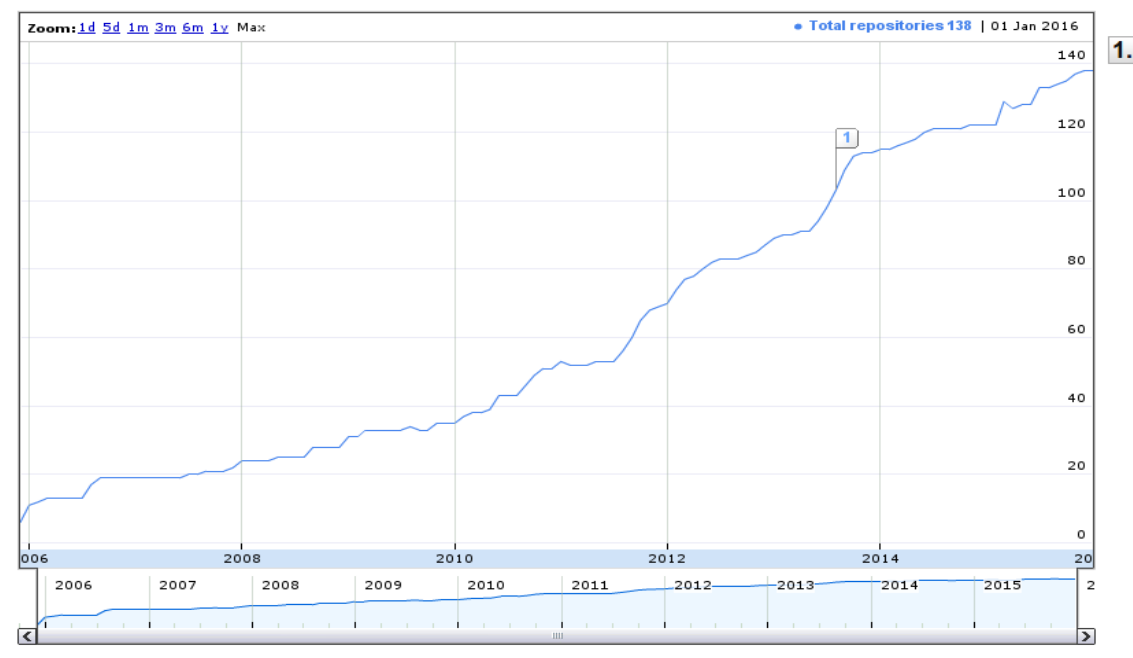

Figure 3. Cumulative growth of OARs (Source: OpenDOAR)

\section{Scope and Limitations}

The model (AgriCat) is based on the architecture of BURA and is configured using DSpace software (version 4.2) (http://www.dspace.org/) and harvesting is done using its (BURA) user interface. OHS (Open Harvester System - https://pkp.sfu.ca/ohs/), version 2.0 developed by PKP (Public Knowledge Project) has been selected as the best fit for the purpose. This study is limited to only agricultural OARs registered in OpenDOAR database. Repositories containing 'Agriculture' as one of the key subject have been considered, although the field 'agriculture' (as shown in OpenDOAR database) covers three broad subjects viz. agriculture, food and veterinary science. An exhaustive review and harvesting of existing agricultural IDRs is out of the scope of this paper. It is a prototype harvesting framework which may be integrated with any Web-enabled retrieval system Only textual objects were harvested and non-textual object types, such as datasets, images and software, etc were 
not harvested. Data was collected from the official websites of these data providers during January March, 2016 and harvesting metadata from selected repositories was done thereon.

\section{AgriCat: The Key Features}

The purpose of this framework is to aggregate all OA research outputs in different form (e.g. theses, dissertations, project reports, etc) and format (e.g. doc, pdf, etc) from agricultural IDRs registered in OpenDOAR database and making it available to the public through a single search gateway. It is an effort to create a unified search interface for cross archive searching. It facilitates free unrestricted access and reuse of OA research outputs for all working in the agricultural field by harvesting openly accessible content available in agricultural OARs recorded in OpenDOAR database. This model harvester named AgriCat has few features that are worth mentioning - i) compatible with open standards and open source software; ii) displays bibliographic records as well as full text; iii) sort by relevance, date, author, title and publication; iv) supports multiple harvesting protocols versions; v) support different metadata standards and languages; vi) allow generation of new plug-ins, patches to the base system; vii) supports distributed searching approach and harvesting approach; viii) refine search; and ix) RSS feeds for live updates.

\section{Methodology: Development of the Prototype}

This section provides a brief theoretical overview of the methodology followed for the development of the solution named AgriCat. It has been developed following current approaches, technologies, standards and best practices. It uses a number of OSS, protocols and open standard technologies in different layers and levels of its implementations. It is based on the software architecture developed in a research work (Roy 2014a) and uses the technical architecture of the BURA framework with some modifications and alternations. A general metadata harvesting mechanism had been proposed in the field of integrating/extracting bibliographic records in distributed digital library system. AgriCat has been introduced here as a harvesting model based on LAMP (Linux-Apache-MySQL-PHP) architecture. It uses Lucene search engine to extract metadata from data providers, the MySQL as relational database, Apache as web server, PHP as programming/scripting language and PKP (version 2.3.2) as harvesting tool. Linux (Ubuntu -14.04.4) is used as operating system. All these software were integrated and deployed in DSpace to achive seamless connectivity to existing IDR. The system has been tested on several different configurations. The designing part is divided into four broad groups - a) selection and installation of software, b) development of LAMP architecture, c) selection and installation of Harvester (here PKP), and) performing and configuring repository related activities. The whole methodology may schemetically be represented here as follows (Figure 4):

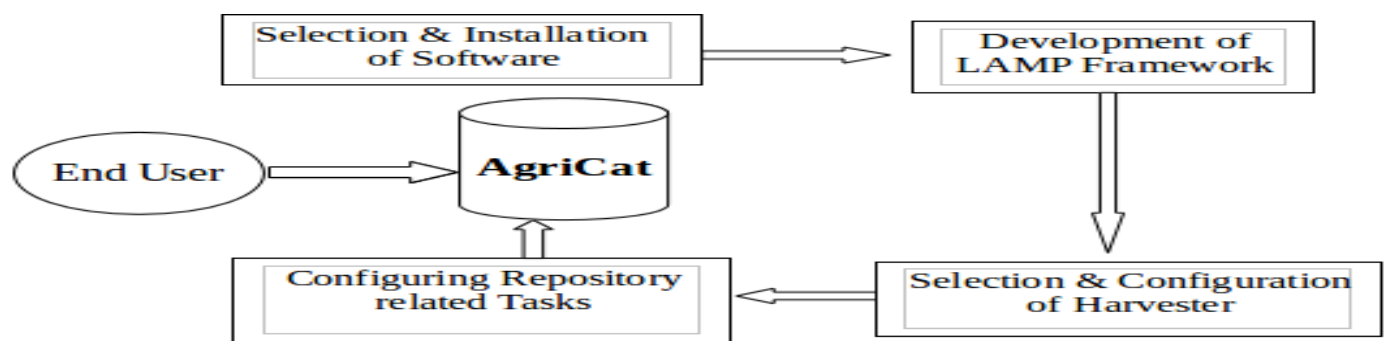

Figure 4. Development of the Model 
As a whole, the methodology (as illustrated in Figure 4) may be explained under following major heads - Group I: Development of Basic cluster by installation and configuation of LAMP architecture; Group II: Selection of harvesting software against a predefined checklist (PKP OHS selected after evaluation agaist a set of craefully crafted parametrs); Group III: Checking of OAI compatibility (by the application of Six OAI verbs) of repositories on Agriculture (as listed in OpenDOAR); Group IV: Adding selected archives in PKP OHS by providing URL, OAI Base URL and associated information (available from OpenDOAR); Group V: Harvesting of metadata from selected OAI compliant repositories on Agriculture; Group VI: Development of centralized index and customization of user interface.

Apart from this, selection of repositories (section 7) and validation testing of OAI-PMH url of repositories (section 8) are also the part of the methodology and have been discussed in subsequent sections. In addition of these steps, section 9 also represents part of the methodology as it is concerned with the customization of interface for performing various system level operations such as addition/ deletion of new repositories, password management, managing of sites, creating sorting order etc.

\section{Selection of Agricultural Repositories}

As mentioned above, out of the 138 OARs (as on January 2016) registered in OpenDOAR database, we have selected 29 repositories (for the first stage of selection) based on carefully crafted criteria mentioned in Table 1 (cf. Roy, Biswas \& Mukhopadhyay 2015). All OARs selected in the first level of study have been reviewed individually and have been tested using OVAL (Open Vulnerability and Assessment Language) validation tool (http://oval.base-search.net/) (Figure 5). This tool is used to check whether the OAI-PMH based URL of the particular repository is working or not. Finally, repositories those qualified in the validation test have been considered for metadata harvesting. For this study, six validation qualified interoperable (e.g. data providers) repositories have been short listed simply to get a representative sample.

Table 1: Parameters for selection of agricultural repositories

\begin{tabular}{|l|l|}
\hline \multicolumn{1}{|c|}{ Parameters/Criteria } & Conditions (Order of preferences) \\
\hline Support for OAI-PMH (version 2) & Available for metadata harvesting \\
Number of objects uploaded & 5,000 and above \\
Type of software used & Distributed architecture \\
Language covered & English only \\
Data type & Textual (at least) \\
Data format & Variety of format supported \\
Data availability & Full text \\
Interface & Web-based \\
Searching & Simple and Advanced (at least) \\
Browsing and Sorting & Metadata elements \\
Metadata schemas & Open standard \\
\hline
\end{tabular}

\section{Validations testing of base OAI-PMH URL}

Validations testing of base OAI-PMH URLs of selected repositories have been conducted by using OVAL validator tool. OAI-PMH validator or OVAL is a Web application that verifies validation of OARs compliance with OAI-PMH. It has been designed to help repository managers to easily verify if their repository is compliant with the BASE (Bielefeld Academic Search Engine) requirements. It supports both generic as well as content-specific validation. It can also detect problems with metadata entries (e.g. invalid URLs, empty title, invalid date formats, etc.). For a sample study, QUT (Queensland University of Technology) ePrints archive has been tested against OVAL validator tool and the result is given in Figure 5. QUT ePrints archive has been short listed as per the criteria mentioned in table 1 . 


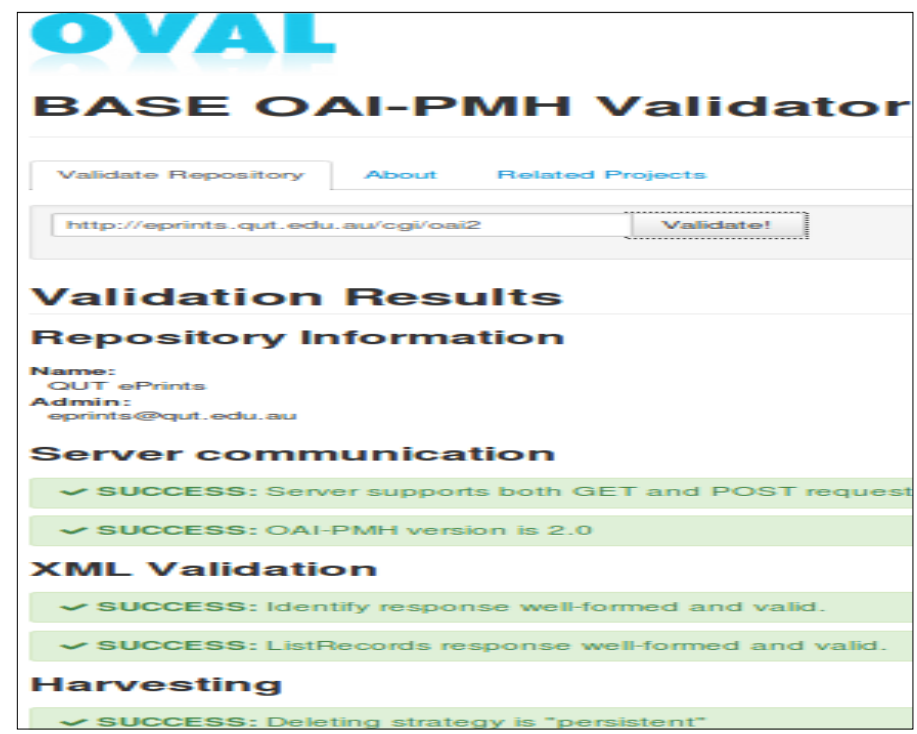

Figure 5. Validations testing of base OAI-PMH URL

\section{Features and Functions of AgriCat}

The model has several features like re-setting password, site management, adding new repository, managing repositories, sorting repositories updating metadata records etc. This section demonstrates some of the key features and functionalities of the proposed metadata harvesting framework from the administrators' point of view.

\subsection{System Level Operations}

Organization and management of repositories is vital task and includes various administrative operations such as password management, editing and managing repositories, creating sorting order etc. (Figure 6).

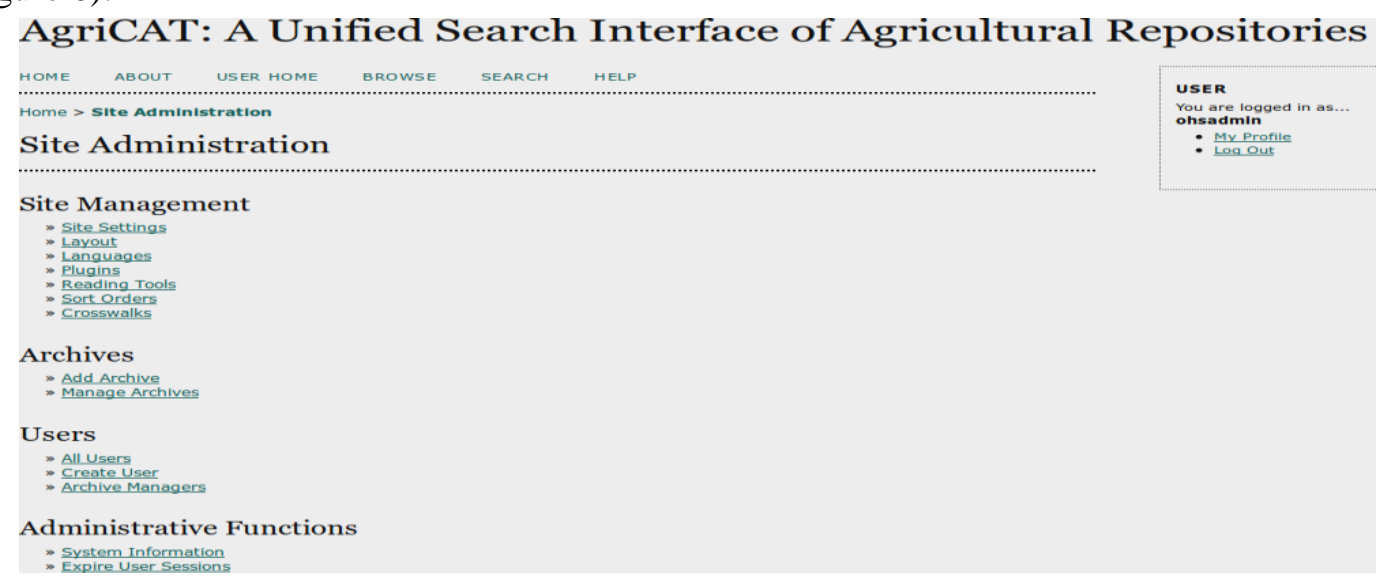

Figure 6. Administrative interface of AgriCat

\subsection{Site Settings}

In addition, administrator can perform system level operations like site management including title and brief information about the service provider, contact details of the administrator etc. (Figure 7). 


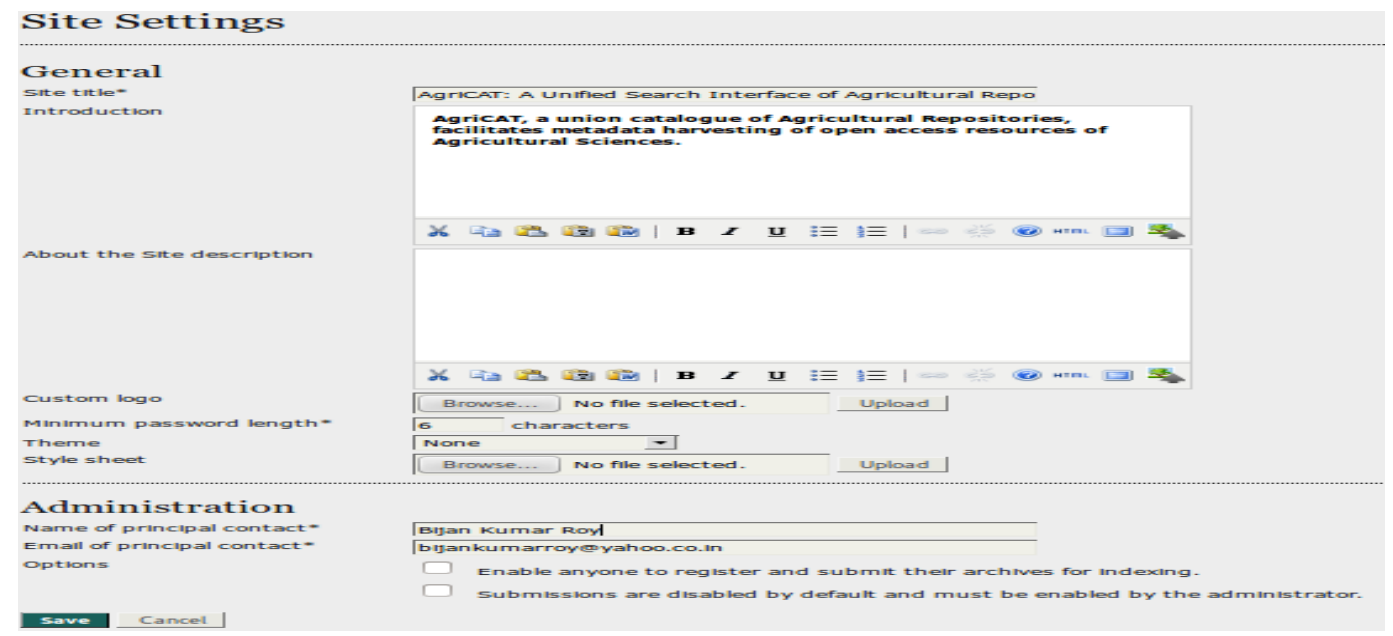

Figure 7. Site management

\subsection{Adding Data Provider to the Harvester}

Like other harvesting framework, this system has the capability to include new OAI-PMH compatible OARs at any time (Figure 8). A number of data providers can be added through the 'Add Archive' interface.

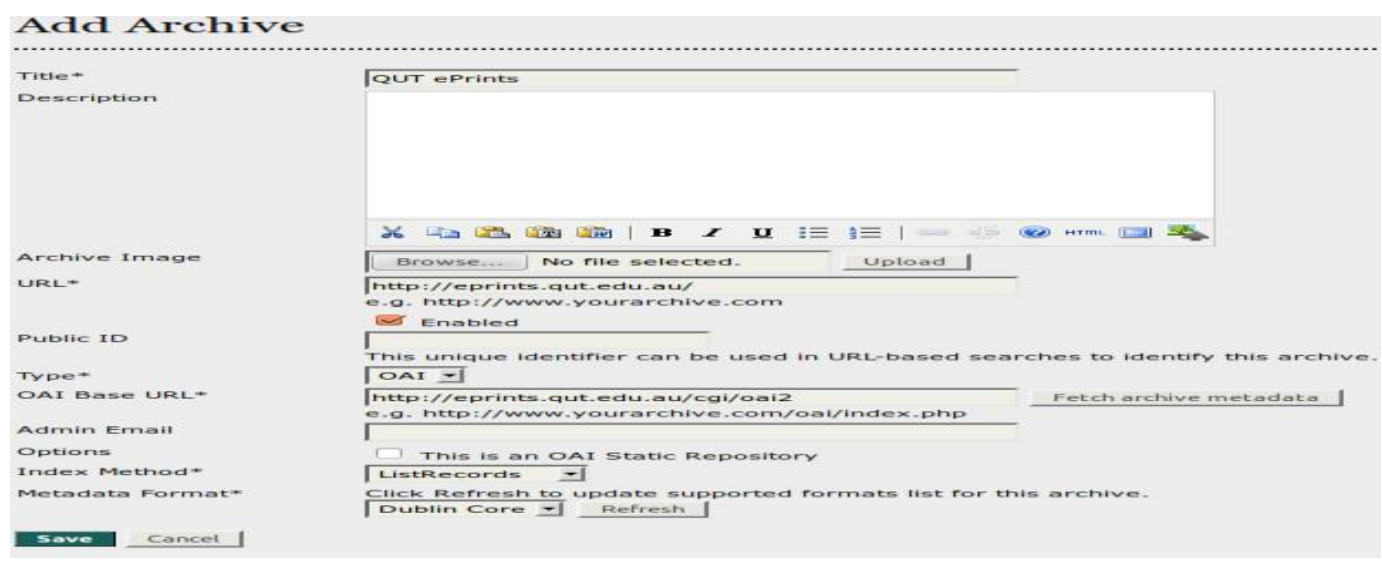

Figure 8. Addition of new repository

\subsection{Updating Metadata Records}

Metadata is important for location, identification and retrieval of documents, and quality of research depends on quality of metadata. The novelty of this model is that system allows updating of metadata records at any time (Figure 9). It (metadata harvesting) can be limited by setting 'Record Dates' or by 'Sets'.

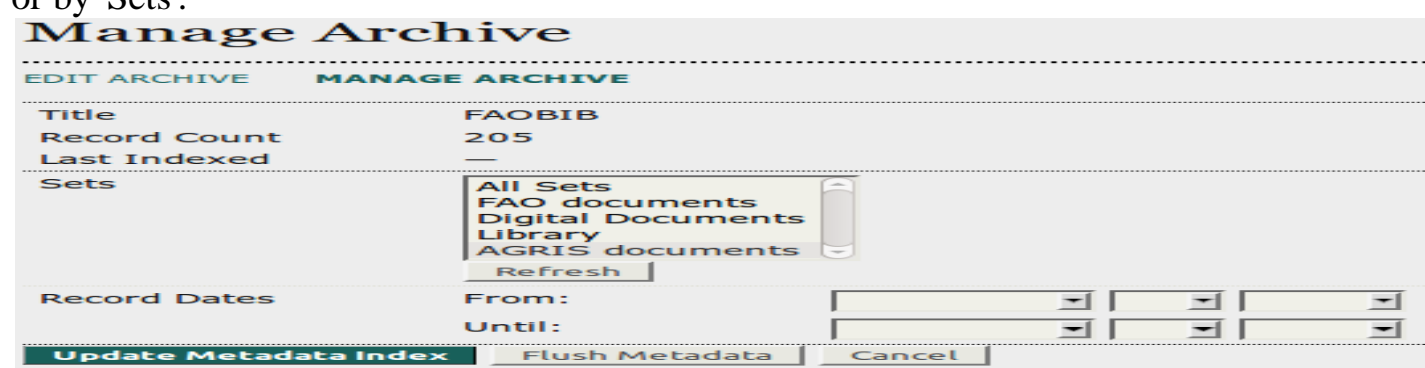

Figure 9. Updating metadata index 


\section{Key Services}

This section outlines some of the key services offered by the model from the users' point of view.

\subsection{Browsing}

AgriCat provides basic services like retrieval of records either by browsing or searching. Figure 10 is the browse view of the model. User can browse content by different access points such as author, title, subject or date.

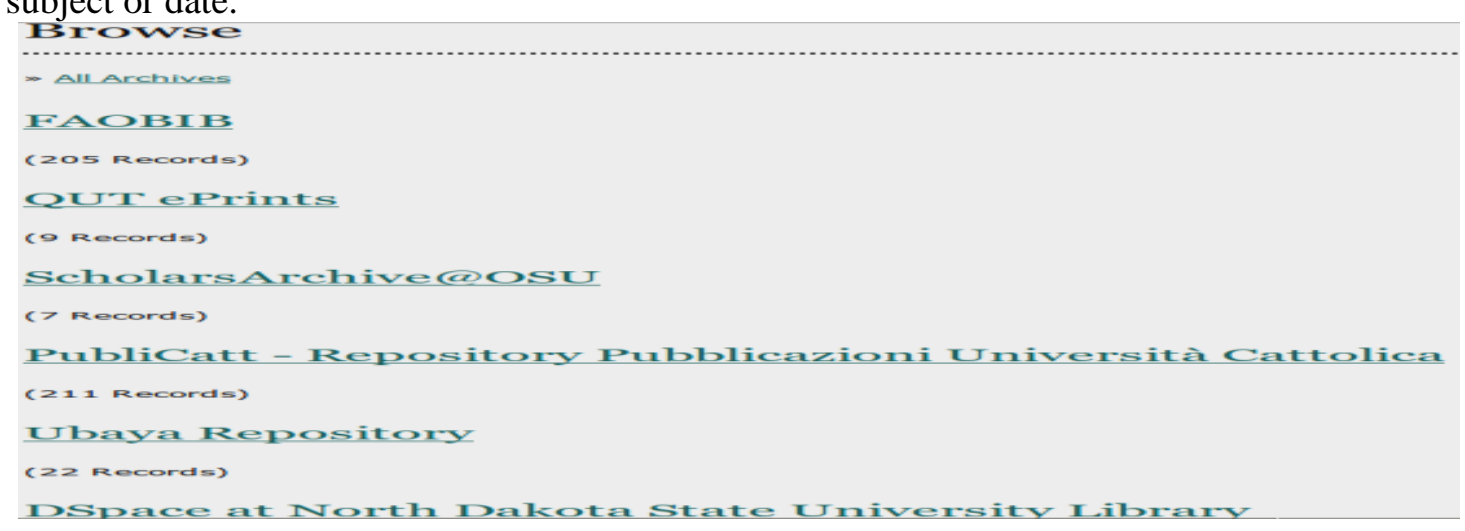

Figure 10. Browsing repositories

\subsection{Searching}

User interface of the framework provides two basic search facilities: i) simple search and ii) advanced search. Simple searching allows users searching free text across archives. Advanced searching allows users restricting his/her search to a specific metadata fields. In addition, the system (e.g. harvester) can search for an exact phrase by putting it in quotes; exclude a word by prefixing it with '-' or NOT; use * in a term as a wildcard to match any sequence of characters. This interface allows user searching a particular repository or all repositories (Figure 11).

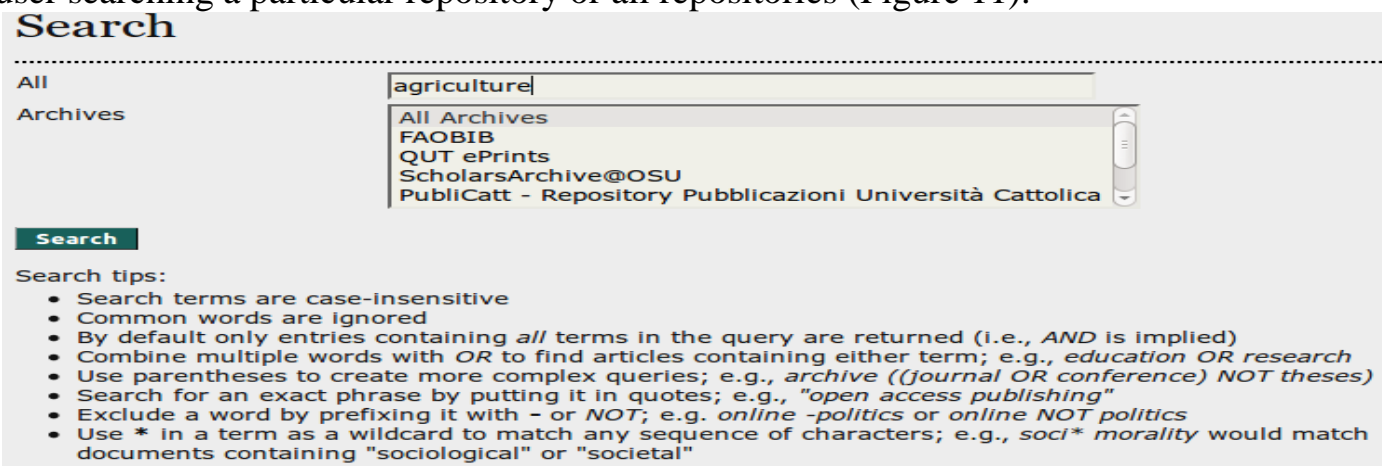

Figure 11. Search interface

The search results against the search term 'agriculture' (Figure 11) is displayed in Figure 12. 


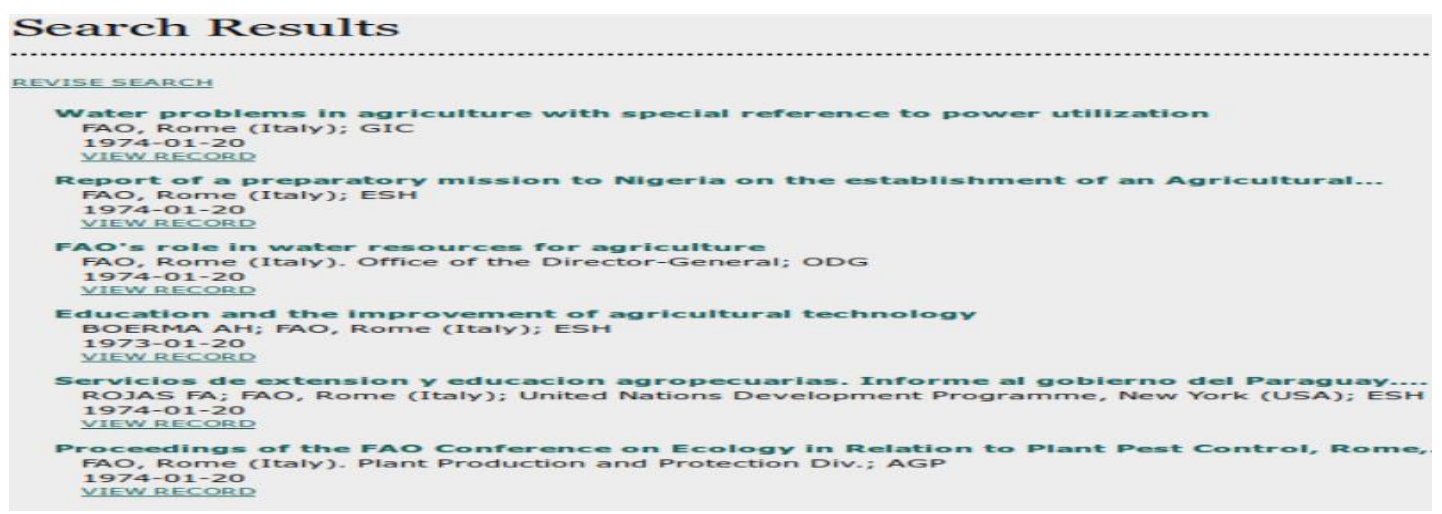

Figure 12. Search results

Figure 13 displays the records in details. When the user clicks the 'View Record' link (Figure 12), the full record will be displayed.

Record Details

\begin{tabular}{l} 
Servicios de extension y educacion agropecuarias. Informe al gobierno del Paraguay. Basado en la \\
labor de F.A. Rojas \\
FAOBIB \\
VIEW ARCHIVE INFO \\
\hline TIELD
\end{tabular}

Figure 13. Record display

Like other harvesting system, this model also allows users searching records by 'Date', by 'Sets' or by 'Domain'.

\section{Findings}

After reviewing all the repositories under study, a number of key findings have been identified. These are - i) immense variations among the granularities and the types of the objects characterized by harvested metadata; ii) non-availability of metadata and no review mechanism for extracted metadata; iii) currency and persistence of metadata; iv) non-existence of OAI-PMH based URL; v) no link to the full text and and some objects with restricted access; vi) Dublin Core metadata elements is the common metadata standard used for displaying metadata; vii) problem regarding updating metadata index; viii) repositories not responding against a search term; ix) syntax problem for the baseURLs of repositories; and x) DSpace has been the common software ued by the data providers.

Agricat, as a local tool for harvesting global OARs on agriculture and related disciplines, has also faced the above listed general problems related to harvesting. It solved most of the listed problems through auto cheking of metadata granularities, datestamp and injected id of the harvested XML records. The quality of descriptive metadata check is beyond the scope of AgriCat and obviously it inherites the harvested metadata as-it-is basis. 


\section{Conclusion}

There is a growing trend of organization and management of agricultural resources and providing global access to these resources through a unified search interface has been a challenging task to the digital library developers. There is no exclusive list of agricultural OARs and due to the non-existence of web-enabled distributed harvesting framework in this domain, attempts have been made to harvest metadata of OARs to support interoperability among globally distributed agricultural information systems. AgriCat solely deals with aggregating resources from agriculture and related subjects and facilitates resource sharing by means of extracting metadata between OAI-based OARs on global scale. This general solution shows how the open knowledge resources from different heterogeneous distributed sources can be harvested and ingested. Basically, it is a mashup application that provides a single search box and enables users' maximum usage and access to open knowledge objects both licensed and free from multiple OAI-based data providers. The development of this new category of search services in agricultural sciences may be considered as an alternative resource discovery platform to the next generation library users by replacing traditional OPAC (Online Public Access Catalogue) system. This feasible solution named AgriCat is applicable to any other discipline or domain and could be useful to the current and prospective service providers who plan to set up new OAI-based services.

\section{References}

Berlin Declaration 2003, Berlin Declaration on Open Access to Knowledge in the Sciences and Humanities.Available from: http://www.zim.mfg.de/openaccessberlin/berlin_declaration.html [21 October 2015].

Bethesda Statement 2003, Bethesda Statement on Open Access Publication. Available from: http://www.earlham.edu/ peters/fos/bethesda.htm [13 October 2015].

Budapest Open Access Initiative 2002, Read the Budapest Open Access Initiative. Available from: http://www.soros.org/openaccess/read.shtml. [13 October 2015].

Crow, R 2002, The Case for Institutional Repositories: A SPARC Position Paper, The Scholarly Publishing \& Academic Resources Coalition, Washington, D.C. Available from: http://www.sparc.arl.org/sites/default/files/ir_final_release_102.pdf [11 December 2015].

Donaldson, RL \& Nelson, DW (2011, The 2012 Promise of Open Access Textbooks: Florida Virtual Campus. Available from: http://www.openaccesstextbooks.org/pdf/ModelDraft.pdf [03 July 2015].

Ganaie, SA. et al. 2014, 'Current trends of the open access digital repositories in library and information science', International Journal of Information Dissemination and Technology, vol. 4, no. 4, pp. 278-282.

Hirwade, M \& Hirwade, A 2006, 'Metadata harvesting services in India', Library Herald, vol. 44, no. 4, pp. 275 282.

Hirwade, MA \& Bherwani, MT 2011, ' Metadata harvesting: tools and services in India', SRELS Journal of Information Management, vol. 48, no. 4, pp. 389-398.

Jayakanth, F, Minj, F \& Dastidar, PG 2012, 'Setting up an open access digital repository: a case study', Annals of Library and Information Studies, vol. 59, no. 1, pp. 16-24.

Jayakanth, F \& Minj, F 2012, 'Federated search service for OAI-compliant open-access repositories in India', International Conference on Trends in Knowledge and Information Dynamics, pp. 1-8. Available from: http://eprints.iisc.ernet.in/43176/1/fj-minj_drtc_ictk_final.pdf [22 April 2014].

Kumar, S, Sanaman, G, \& Rai, N 2008, 'Federated search: new option for libraries in the digital era, $6^{\text {th }}$ International CALIBER, University of Allahabad, Allahabad, February 28-29 \& March 01, pp. 267-285.

Liu, X. et al. 2001, 'Arc: an OAI service provider for cross-archive searching. Proceedings of the $1^{\text {st }}$ ACM/IEEECS joint conference on Digital libraries, pp. 65-66. Available from: http://dl.acm.org/citation.cfm?Id=379451 [04 August 2015].

Marcondes, CH \& Sayao, LF, 2003, 'Brazilian Digital Library of Theses and Dissertations', International Information and Library Review', vol. 35, no. 2-4, pp. 265-279. doi:10.1016/S1057-2317(03)00016-X 
Mukhopadhyay, P 2015, Open Access for Library Schools: Module 4: Interoperability and Retrieval, UNESCO, Paris. Available from: http://unesdoc.unesco.org/images/0023/002321/232199E.pdf [15 January 2016].

OpenDOAR 2016, Directory of Open Access Repositories. Available from: http://www.opendoar.org/ [02 January 2016].

ROAR 2016, Registry of Open Access Repositories. Available from: http://roar.eprints.org/ [13 October 2015].

Roy, BK 2007, 'Indian initiatives in the development of institutional digital repository. Digital Media and library Information Services, Proceedings of $26^{\text {th }}$ IASLIC Conference, Jamia Millia Islamia, New Delhi, December 2627, 2007, pp. 253-262.

Roy, BK 2010, 'Open access trends and developments in India', Librarian, vol. 17, pp. 83-87.

Roy, BK 2014a, Designing Institutional Digital Repository for the University of Burdwan: A FLOSS Based Prototype, PhD Thesis, The University of Burdwan.

Roy, BK 2014b, 'Open access repository: an alternative model for scholarly communication' in Charaibeti: Golden Jubilee Commemorative Volume, eds. G Maity \& Others, Jadavpur University, Kolkata, pp. 250 - 257.

Roy, BK 2015, Institutional Digital Repository: From Policy to Practice, LAP, Germany.

Roy, BK \& Mukhopadhyay, P 2011, 'Development of learning objects repositories in India', Open Access: Gateway to Open Innovation, Proceedings of the $27^{\text {th }}$ Annual Conference of the Society for Information Science, Kolkata, India, November 24-27, 2010, pp. 179-187.

Roy, BK, Biswas, SC \& Mukhopadhyay, P 2012a, 'An analytical study of institutional digital repositories in India', Library Philosophy and Practice, Paper 692. Available from: http://digitalcommons.unl.edu/libphilprac/692 [22 December 2015].

Roy, BK., Biswas, SC \& Mukhopadhyay, P 2012b, 'Open access repositories in Asia: from SAARC to Asian tigers', Library Philosophy and Practice, Paper 808. Available from: http://digitalcommons.unl.edu/libphilprac/808 [22 December 2015].

Roy, BK, Biswas, SC \& Mukhopadhyay, P 2012c, 'Open access to scholarly information in India: trends and developments', International Research: Journal of Library \& Information Science, vol. 2, no. 1, pp. 89-101.

Roy, BK, Biswas, SC \& Mukhopadhyay, P 2012d, 'Study of open access repositories: a global perspective', Information-Innovation-Technology: Creating Seamless Linkages, $29^{\text {th }}$ Convention \& Conference of Society of Information Science, Silchar, National Institute of Technology, November 26-28, 2012.

Roy, BK, Biswas, SC \& Mukhopadhyay, P 2013, 'Global visibility of Indian open access institutional digital repositories', International Research: Journal of Library \& Information Science, vol. 3, no. 1, pp 182-194.

Roy, BK., Biswas, SC \& Mukhopadhyay, P 2015, 'Trends and developments of open access repository movement in Europe', International Research: Journal of Library and Information Science, vol. 5, no. 3, pp. 407-422.

Roy, BK, Biswas, SC \& Mukhopadhyay, P 2016a, 'Status of open access institutional digital repositories in agricultural sciences: a case study of Asia', Library Philosophy and Practice, Paper 1329. Available from: http://digitalcommons.unl.edu/libphilprac/1329 [16 December 2015].

Roy, BK, Biswas, SC \& Mukhopadhyay, P 2016b, 'The COAPI cats: the current state of open access repository movement and policy documentations', International Journal of Knowledge Content Development \& Technology. [Accepted for publication].

Roy, BK, Biswas, SC \& Mukhopadhyay, P 2016c, 'Global repository movement in the domain of library and information science', International Journal of Information Science and Management. [Accepted for publication].

Roy, BK, Biswas, SC., \& Mukhopadhyay, P 2016d, 'Open access repositories for Indian universities: towards a multilingual framework', IASLIC Bulletin. [Accepted for publication].

Roy, BK., Biswas, SC \& Mukhopadhyay, P 2016e, 'Designing metadata harvesting framework for OAI-based LIS repositories: a prototype', International Journal of Information Science and Management. [Mss. submitted].

Sarkar, P \& Mukhopadhyay, P 2010, 'Designing single-window search service for electronic theses and dissertations through metadata harvesting', Annals of Library and Information Studies, vol. 57, no. 4, pp. 356364. 
Sarkar, P, \& Mukhopadhyay, P 2012a, 'Developing virtual union catalogue of ETDs on health and medicine: a practical approach', Proceeding of the National Seminar on Challenges in Library Management System, Indian Association for the Cultivation of Science, Kolkata, pp. 334-340.

Sarkar, P, \& Mukhopadhyay, P 2012b, 'Metadata and discovery of electronic theses and dissertations' in Trends and Development in Library and Information Science, eds R Tiwari \& Others, Zenith Publications, New Delhi, pp. 315-323.

Sarkar, P, \& Mukhopadhyay, P 2015, 'Interoperability, Open access and ETDs: the development of Indian initiatives', Proceedings of $18^{\text {th }}$ International Symposium on Electronic Theses and Dissertations: Evolving Genre of ETDs for Knowledge Discovery, Jawaharlal Nehru University, New Delhi, pp. 290-302.

Sengupta, S 2012, 'Open access repositories: the Asian scenario with special reference to library \& information science', Redesigning Libraries \& Information Centres in Digital Era, Degloor, Nanded, Maharashtra, pp. 104111. Available from: http://eprints.rclis.org/18129/ [13 October 2015]. 